\title{
PENGARUH POSISI PENGELASAN DAN JENIS ELEKTRODA E 7016 DAN E 7018 TERHADAP KEKUATAN TARIK HASIL LAS BAJA KARBON RENDAH TRS 400
}

\author{
Irzal, Muhammad Fadhil, Syahrul \\ Jurusan Teknik Mesin, Fakultas Teknik Universitas Negeri Padang \\ Corresponding Author: irzalk3@ft.unp.ac.id
}

\begin{abstract}
Abstrak
Beberapa faktor yang mempengaruhi hasil kekuatan pengelasan, diantaranya posisi pengelasan. Posisi pengelasan akan memberikan hasil yang berbeda terhadap kekuatan hasil pengelasan. Jenis elektroda las juga sangat mempengaruhi karakteristik hasil pengelasan, pada sisi lain jenis elektroda untuk pengelasan sering menjadi pilihan pribadi tukang las tanpa memperhatikan kekuatan lasnya. Tujuan penelitian ini dilakukan untuk menganalisa kekuatan tarik terbaik dari posisi pengelasan dan jenis elektroda E 7016 dan E 7018 yang dipakai untuk mengelas baja TRS 400. Penelitian ini merupakan penelitian ekperimen yang digunakan untuk mengetahui pengaruh posisi pengelasan dan jenis elektroda terhadap kekuatan tarik baja karbon rendah TRS 400. Dimana hasil pengujian diperoleh melalui percobaan langsung terhadap benda uji. Berdasarkan hasil penelitian, posisi pengelasan yang menghasilkan kekuatan tarik tertinggi adalah posisi vertikal dengan nilai rata-rata tertinggi $65,52\left(\mathrm{Kgf} / \mathrm{mm}^{2}\right)$. Jenis elektroda yang menghasilkan kekuatan tarik tertinggi adalah elektroda E 7016 dengan nilai rata-rata tertinggi 65,52 $\left(\mathrm{Kgf} / \mathrm{mm}^{2}\right)$. Dibandingkan dengan elektroda E 7018 dengan nilai rata-rata kekuatan tertingg 60,26 (Kgf/mm²). Pada posisi pengelasan vertikal dengan nilai rata-rata kekuatan tertinggi $60,26\left(\mathrm{Kgf} / \mathrm{mm}^{2}\right)$. Dengan demikian posisi dan jenis elektroda yang terbaik dipakai untuk mengelas baja TRS 400 adalah pada posisi vertikal dengan elektroda E 7016.
\end{abstract}

Kata Kunci : Posisi Pengelasan, Jenis Elektroda, KekuatanTarik, dan Baja TRS 400.

\begin{abstract}
Some of the factors that affect the outcome of the strength of welding, including welding position. Welding position will give different results on the strength of the weld. Type welding electrodes are also greatly affect the characteristics of the weld, on the other hand the type of electrode for welding is often a personal choice regardless welder lasnya strength. The purpose of this study conducted to analyze the best tensile strength of the welding position and the type of electrode E 7016 and E 7018 used to weld steel TRS 400. This study is an experimental research are used to determine the effect of welding position and the type of electrode tensile strength carbon steel TRS 400. Where the test results obtained through direct experiments to test object. Based on this research, welding position which produces the highest tensile strength is a vertical position with the highest average value of $65.52\left(\mathrm{kgf} / \mathrm{mm}^{2}\right)$. Types of electrodes that generate the highest tensile strength is the electrode $E 7016$ with the highest average value of $65.52\left(\mathrm{kgf} / \mathrm{mm}^{2}\right)$. Compared with electrodes E 7018 with an average value of 60.26 utmost strength $\left(\mathrm{kgf} / \mathrm{mm}^{2}\right)$. In the vertical welding position with an average value of 60.26 the highest strength $\left(\mathrm{kgf} / \mathrm{mm}^{2}\right)$. Thus the position and type of electrode is best used for welding steel TRS 400 is in a vertical position with the electrode E 7016.
\end{abstract} Keywords: Position Welding, Type Electrodes, Tensile Strength, and Steel TRS 40

\section{Pendahuluan}

Teknik las busur listrik dengan elektroda terbungkus sangat banyak dinggunakan untuk penyambungan batang-batang pada kontruksi bangunan dan kontruksi mesin. Banyaknya penggunaan peyambungan ini disebabkan karena kontruksi bangunan dan mesin yang dibuat dengan teknik penyambungan ini lebih ringan dan proses pembuatannya juga lebih sederhana sehingga biaya keseluruhan lebih rendah. Welding adalah salah satu teknik penyambungan logam dengan cara mencairkan penambah dan menghasilkan sambungan yang kontinyu. Berdasarkan definisi dari DIN (Deutch Industrie Normen) las adalah ikatan metalurgi pada sambungan logam paduan yang dilaksanakan dalam keadaan lumer atau cair. Dengan kata lain las adalah sambungan setempat dari beberapa batang logam dengan menggunakan energi panas.

Pengelasan merupakan suatu hal yang tidak dapat dipisahkan dari pertumbuhan peningkatan industri karena memegang peranan besar dalam rekayasa dan reparasi poduksi logam. Hampir tidak mungkin pembangunaan suatu pabrik tidak melibatkan unsur pengelasan. Ruang lingkup penggunaan teknik pengelasan dalam bidang kontruksi sangat luas, meliputi perkapalan, jembatan, rangka baja, pipa saluran, pembuatan mobil, dan lain sebagainya. Di samping itu pengelasan dingunakan untuk reparasi misalnya untuk mengisi lubang-lubang pada coran, mempertebal bagian-bagian yang sudah haus dan lain sebagainya. 
Sering kali pengelasan harus dilakukan pada posisi tertentu karena mengikuti rancangan suatu kontuksi seperti pengelasan langit-langit/plafon bangunan, pada pojok bangunan, dan sebagainya. Terlebih lagi pada poses pengelasan berkelanjutan yaitu suatu kontruksi memerlukan penegelasan yang berurutan dan cepat dengan posisi pengelasan yang berbedabeda. Dengan adanyan keharusan posisi pengelasan terntu, maka akan memberikan hasil yang berbeda terhadap kekuatan hasil lasan (Cary,1998).

Kualitas pengelasan sangat ditentukan oleh beberapa faktor. Menurut Daryanto (2012:11) beberapa faktor tersebut antara lain posisi mengelas, bahan logam yang disambung, pengaruh panas, jenis kampuh yang tepat serta jeni elektroda yang digunakan. Banyak pekerja di bidang pengelasan yang tidak mengetahui tentang penggunaan elektroda terhadap jenis posisi pengelasan dan ketebalan bahan yang akan digunakan dalam proses pengelasan.

Jenis elektroda las juga sangat merpengaruhi karakteristik hasil lasan, pada sisi lain jenis elektroda untuk pengelasan sering menjadi pilihan pribadi tukang las itu sendiri tanpa memperhatikan kekuatan lasnya. Untuk mengetahui posisi pengelasan dan jenis elektroda yang menghasilkan sifat yang paling baik, perlu dilakukan penelitian dan pengujian. Dari salah satu sifak mekanik yang paling penting dalam pengelasan adalah sifat kekuatan tarik.

\section{A. Baja}

Baja adalah campuran besi dan karbon, dengan kandungan karbon maksimum 1,5\%. Karbon terjadi dalam wujud karbid besi, sehingga meningkatkan kekerasan baja. Baja merupakan paduan besi dan karbon yang dapat berisi konsentrasi dari elemen campuran lainnya. Ada ribuan campuran logam lainnya yang mempunyai komposisi berbeda. Sifat mekanis dari baja sangat sensitif terhadap kandungan karbon, yang mana secara normal kurang dari 1,5\%. Sebagian dari baja digolongkan menurut konsentrasi karbon, yakni ke dalam baja karbon rendah, sedang dan tinggi.

Penelitian ini menggunakan bahan baja TRS 400 sebagai bahan penelitian. Baja TRS 400 termasuk ke dalam baja karbon rendah karena mengandung karbon kurang dari $0.30 \%$. Karakteristik dari baja TRS 400 ini mudah untuk fabrikasi, ketangguhan dan ketahanan aus yang baik. Baja TRS 400 banyak digunakan pada kontruksi umum, pabrik semen, industri besi dan baja, dan pertambangan batu bara. Untuk spesifikasi baja TRS 400 dapat dilihat pada tabel 2 di bawah ini.
Tabel 1. Spesifikasi Baja TRS 400

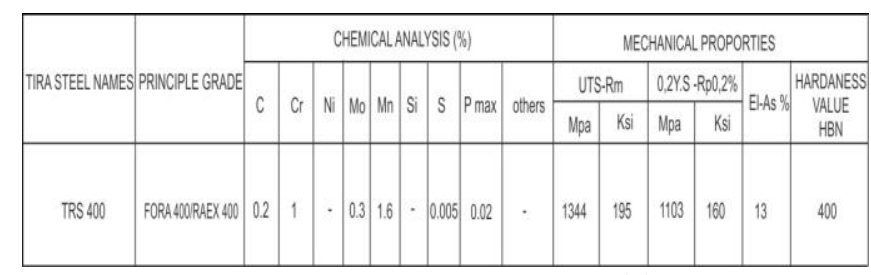

(PT. TIRA AUSTENITE Tbk)

\section{B. Pengelasan SMAW}

Shielded Metal Arc Welding (SMAW) dikenal juga dengan istilah Manual Metal Arc Welding (MMAW) atau Las elektroda terbungkus adalah suatu proses penyambungan dua keping logam atau lebih, menjadi suatu sambungan yang tetap, dengan menggunakan sumber panas listrik dan bahan tambah/pengisi berupa elektroda terbungkus. Pada proses las elektroda terbungkus, busur api listrik yang terjadi antara ujung elektroda dan logam induk/benda kerja(base metal) akan menghasilkan panas.

Busur listrik yang terjadi di antara ujung elektroda dan bahan dasar akan mencairkan ujung elektroda dan sebagian bahan dasar. Selaput elektroda yang turut terbakar akan mencairkan dan menhasilkan gas yang melindungi ujung elektroda dan kawah las, melindungi busur listrik terhadap pengaruh udara luar. Cairan selaput elektroda yang membeku akan menutupi permukaan las yang juga berfungsi sebagai pelindung terhadap pengaruh luar.

\section{Elektroda}

Bagian terpenting dalam las busur listrik adalah elektroda las. Jenis elektroda yang dipergunakankan menentukan hasil pengelasan sehingga sangat penting untuk mengetahui sifat dan jenis dari masing-masing elektroda sebagai dasar pemilihan elektroda yang tepat. Jenis elektroda yang dipergunkan menentukan hasil pengelasan sehingga sangat penting untuk mengetahui sifat dan jenis dari masing-masing elektroda sebagai dasar pemilihan elektroda yang tepat Fenny Sartika (2015:13)

Menurut I Gusti Ngurah Nitya Santhiarsadan I Nyoman Budiarsa (2007 : 107) Elektroda Pada dasarnya bila ditinjau dari logam yang dilas kawat elektroda dibedakan menjadi lima, yaitu : baja lunak, baja karbon tinggi, baja paduan, besi tuang dan logam non ferro. Karena filler metal harus mempunyai kesamaan sifat dengan logam induk,maka sekaligus ini berarti setiap dengan jenis bahan yang akan dilas. Kawat Elektroda terdiri dari dua bagian yaitu bagian yang berselaput (fluks) dan tidak berselaput yang merupakan pangkal untuk menjepitkan tang las. Sedangkan fungsi fluks sendiri adalah menhasilkan gas pelindung untuk melindungi logam cair dari pengaruh udara luar, menstabilkan/memantapkan 
busur, pengatur penggunaan dan sebagai unsur paduan.

Menurut Daryanto (2012:61) elektroda baja lunak dan baja paduan rendah untuk las busur listrik menurut klasifikasi AWS (American Welding Society) dinyatakan dengan tanda E XXXX yang artinya sebagai berikut:

$\mathrm{E}=$ Menyatakan elektroda busur listrik.

$\mathrm{XX}=$ (angka pertaama dan kedua) sesudah $\mathrm{E}$ menyatakan kekuatan tarik deposit las dalam ribuan $\mathrm{lb} / \mathrm{in}^{2}$.

$\mathrm{X}=$ (angka ketiga) menyatakan posisi pengelasan. Angka 1 untuk pengelasan segala posisi. Angka 2 untuk pengelasan posisi datar di bawah tangan.

$\mathrm{X}=$ (angka keempat) menyatakan jenis selaput dan jenis arus yang cocok dipakai untuk pengelasan.

Menurut Daryanto (2012:63) Selaput elektroda jenis ini mengandung hydrogen yang rendah (kurang dari $0,5 \%$ ), sehingga deposit las juga dapat bebas dari porositas. Elektroda ini dipakai untuk pengelasan yang memerlukan mutu tinggi, bebas porositas, misalnya untuk pengelasan bejana dan pipa yang akan mengalami tekanan. Jenis-jenis elektroda hydrogen rendah misalnya E 7015, E 7016 dan E 7018. Selaput elektroda jenis E 6027, E 7014. E 7018. E 7024 dan E 7028 mengandung serbuk besi untuk meningkatkan efisiensi pengelasan. Umumnya selaput elektroda akan lebih tebal dengan bertambahnya persentase serbuk besi.

\section{Metode penelitian}

Peneltian ini merupakan penelitian ekperimen yang digunakan untuk mengetahui pengaruh posisi pengelasan dan jenis elektroda terhadap kekuatan tarik terhadap baja karbon rendah TRS 400. Metode penelitian ekperimen dapat diartikan sebagai metode penelitian yang digunakan untuk mencari pengaruh perlakuan tertentu terhadap yang lain dalam kondisi yang terkendali (Sugiyono 2012:72). Dimana hasil pengujian diperoleh melalui percobaan langsung terhadap benda uji. Berdasarkan pokok masalah yang dibahas dalam bab sebelumnya, maka data penelitian berupa hasil pengujian kekuatan tarik selanjutnya diamati dan di analisa untuk mengetahui ada atau tidaknya pengaruh hasil pengelasan terhadap kekuatan bahan yang dilas.

Waktu pelaksanaan penelitian ini dilakukan dalam jangka waktu 4 bulan (Oktober 2016 - Januari 2017). Mulai dari pengajuan proposal, pembuatan spesimen, pengujian, sampai ke pembuatan laporan. Penelitian uji tarik ini dilaksanakan di laboratorium pengujian bahan jurusan Teknik Sipil Universitas Negeri Padang.
Objek penelitian yang diteliti adalah posisi pengelasa dengan menggunakan plat baja karbon rendah (TRS 400) dengan tebal $8 \mathrm{~mm}$ hasil dari pengelasan SMAW dengan menggunakan dua jenis elektroda yaitu E 7016 dan E $7018 \varnothing$ 3,2 merek Kobe Steel. Masingmasing posisi pemgelasan dan jenis elektroda mempunyai 3 spesimen yang diuji menggunakan alat uji tarik.

\section{Hasil Penelitian}

\section{A. Hasil Pengujian Tarik}

Setelah melakukan pengujian tarik yang dilaksanakan di laboratorium Kontruksi Jurusan Teknik Sipil Universitas Negeri Padang, maka dapat ditentukan hasil kekuatan tarik $(\sigma)$ baja karbon rendah TRS 400 menggunakan rumus sebagai berikut :

$\sigma \mu=\frac{F \max }{A o} \quad\left(\mathrm{~N} / \mathrm{mm}^{2}\right)$

Dimana: $\sigma \mu \quad=$ Kekuatan $\operatorname{tarik}\left(\mathrm{N} / \mathrm{mm}^{2}\right)$

$$
\begin{gathered}
\text { Fmax }=\text { Beban maxsimun (Newton) } \\
A o=\text { luas penampang awal }\left(\mathrm{mm}^{2}\right)
\end{gathered}
$$

Spesimen A (posisi bawah tangan dengan E 7016)

$\sigma \mu=\frac{F \max }{A o}=\frac{134 \mathrm{kN}}{200 \mathrm{~mm}^{2}}=670 \mathrm{~N} / \mathrm{mm}^{2}=$

$\mathrm{kg} / \mathrm{mm}^{2}$

$\sigma \mu=\frac{F \max }{A o}=\frac{118 \mathrm{kN}}{210 \mathrm{~mm}^{2}}=561,9 \mathrm{~N} / \mathrm{mm}^{2}=$

$\mathrm{kg} / \mathrm{mm}^{2}$

$\sigma \mu=\frac{F \max }{A o}=\frac{130 \mathrm{kN}}{210 \mathrm{~mm}^{2}}=619,05 \mathrm{~N} / \mathrm{mm}^{2}=$ $\mathrm{kg} / \mathrm{mm}^{2}$

Spesimen B (posisi vertikal dengan E 7016)

$\sigma \mu=\frac{F \max }{A o}=\frac{139 \mathrm{kN}}{210 \mathrm{~mm}^{2}}=661,9 \mathrm{~N} / \mathrm{mm}^{2}=$

$\mathrm{kg} / \mathrm{mm}^{2}$

$\sigma \mu=\frac{F \max }{A o}=\frac{131 \mathrm{kN}}{210 \mathrm{~mm}^{2}}=623,81 \mathrm{~N} / \mathrm{mm}^{2}=$

$\mathrm{kg} / \mathrm{mm}^{2}$

$\sigma \mu=\frac{F \max }{A o}=\frac{135 \mathrm{kN}}{210 \mathrm{~mm}^{2}}=642,86 \mathrm{~N} / \mathrm{mm}^{2}=$

$\mathrm{kg} / \mathrm{mm}^{2}$

Spesimen C (posisi horizontal dengan E 7016)

$\sigma \mu=\frac{F \max }{A o}=\frac{130 \mathrm{kN}}{210 \mathrm{~mm}^{2}}=619,05 \mathrm{~N} / \mathrm{mm}^{2}=63,10$ $\mathrm{kg} / \mathrm{mm}^{2}$

$\sigma \mu=\frac{F \max }{A o}=\frac{139 \mathrm{kN}}{220 \mathrm{~mm}^{2}}=631,82 \mathrm{~N} / \mathrm{mm}^{2}=64,40$ $\mathrm{kg} / \mathrm{mm}^{2}$

$\sigma \mu=\frac{F \max }{A o}=\frac{129 \mathrm{kN}}{210 \mathrm{~mm}^{2}}=614,29 \mathrm{~N} / \mathrm{mm}^{2}=$ 
Spesimen D (posisi bawah tangan dengan E 7018)

$\sigma \mu=\frac{F \max }{A o}=\frac{114 \mathrm{kN}}{210 \mathrm{~mm}^{2}}=542,86 \mathrm{~N} / \mathrm{mm}^{2}=$ $\mathrm{kg} / \mathrm{mm}^{2}$

$\sigma \mu=\frac{F \max }{A o}=\frac{122 \mathrm{kN}}{210 \mathrm{~mm}^{2}}=580,95 \mathrm{~N} / \mathrm{mm}^{2}=59,22$ $\mathrm{kg} / \mathrm{mm}^{2}$

$\sigma \mu=\frac{F \max }{A o}=\frac{87 \mathrm{kN}}{210 \mathrm{~mm}^{2}}=414,29 \mathrm{~N} / \mathrm{mm}^{2}=$

$\mathrm{kg} / \mathrm{mm}^{2}$

Spesimen E (posisi vertikal dengan E 7018)

$\sigma \mu=\frac{F \max }{A o}=\frac{99 \mathrm{kN}}{210 \mathrm{~mm}^{2}}=471,43 \mathrm{~N} / \mathrm{mm}^{2}=48,07$ $\mathrm{kg} / \mathrm{mm}^{2}$

$\sigma \mu=\frac{F \max }{A o}=\frac{136 \mathrm{kN}}{220 \mathrm{~mm}^{2}}=618,18 \mathrm{~N} / \mathrm{mm}^{2}=$

$\mathrm{kg} / \mathrm{mm}^{2}$

$\sigma \mu=\frac{F \max }{A o}=\frac{150,5 \mathrm{kN}}{220 \mathrm{~mm}^{2}}=684,09 \mathrm{~N} / \mathrm{mm}^{2}=$ $\mathrm{kg} / \mathrm{mm}^{2}$

Spesimen F (posisi horizontal dengan elektroda E 7018)

$\sigma \mu=\frac{F \max }{A o}=\frac{126 \mathrm{kN}}{210 \mathrm{~mm}^{2}}=600 \mathrm{~N} / \mathrm{mm}^{2}=$

$\mathrm{kg} / \mathrm{mm}^{2}$

$\sigma \mu=\frac{F \max }{A o}=\frac{82 \mathrm{kN}}{220 \mathrm{~mm}^{2}}=372,73 \mathrm{~N} / \mathrm{mm}^{2}=$

$\mathrm{kg} / \mathrm{mm}^{2}$

$\sigma \mu=\frac{F \max }{A o}=\frac{124 \mathrm{kN}}{220 \mathrm{~mm}^{2}}=563,64 \mathrm{~N} / \mathrm{mm}^{2}=$

$\mathrm{kg} / \mathrm{mm}^{2}$

Spesimen kontrol

$\sigma \mu=\frac{F \max }{A o}=\frac{251 \mathrm{kN}}{210}=1.195,24 \mathrm{~N} / \mathrm{mm}^{2}=121,83$ $\mathrm{kg} / \mathrm{mm}^{2}$

$\sigma \mu=\frac{F \max }{A o}=\frac{271 \mathrm{kN}}{220 \mathrm{~mm}^{2}}=1.231,82 \mathrm{~N} / \mathrm{mm}^{2}=$ $125,56 \mathrm{~kg} / \mathrm{mm}^{2}$

$\sigma \mu=\frac{F \max }{A o}=\frac{261 \mathrm{kN}}{210 \mathrm{~mm}^{2}}=1.242,86 \mathrm{~N} / \mathrm{mm}^{2}=126,69$

$\mathrm{kg} / \mathrm{mm}$

Perhitungan kekuatan tarik di atas, maka dapat diambil nilai rata-rata dari hasil data spesimen uji tarik dengan menggunakan masing-masing variasi jenis elektroda (E 7016 dan E 7018) dan jenis posisi pengelesan (posisi bawah tangan, vertikal, dan horizontal), untuk menentukan nilai kekuatan tarik mana yang lebih besar pada pengujian yang dilakukan oleh peneliti.

Setelah melakukan pengujian tarik yang dilaksanakan di laboratorium Kontruksi Jurusan Teknik Sipil Universitas Negeri Padang, maka dapat ditentukan hasil kekuatan tarik $(\sigma)$ baja karbon rendah TRS 400 seperti pada tabel berikut :

\begin{tabular}{|c|c|c|c|c|c|}
\hline \multirow[b]{2}{*}{ No } & \multirow{2}{*}{$\begin{array}{l}\text { Spes uji(jenis posisi } \\
\text { pengelsan dan jenis } \\
\text { elektroda) }\end{array}$} & \multicolumn{4}{|c|}{ specimen $\left(K g f / m^{2}\right)$} \\
\hline & & 1 & 2 & 3 & $\begin{array}{c}\text { Rata - } \\
\text { Rata }\end{array}$ \\
\hline 1 & $\begin{array}{lr}\text { Spes A } & \text { (posisi } \\
\text { bawah } & \text { tangan } \\
\text { dengan E7016) }\end{array}$ & 68,29 & 57,27 & 63,10 & 62,88 \\
\hline 2 & $\begin{array}{lll}\text { Spes B } & \text { (posisi } \\
\text { vertikal } & \text { dengan } \\
\text { E7016) } & \end{array}$ & 67,47 & 63,58 & 65,53 & 65,52 \\
\hline 3 & $\begin{array}{l}\text { Spes C } \\
\text { horizontal } \\
\text { E7016) }\end{array}$ & 63,10 & 64,40 & 62,61 & 63,39 \\
\hline 4 & $\begin{array}{lrr}\begin{array}{l}\text { Spes } \\
\text { bawah }\end{array} & \text { (posisi } \\
\text { dengan E7018) } & \text { tangan }\end{array}$ & 55,33 & 59,22 & 42,23 & 52,26 \\
\hline 5 & $\begin{array}{l}\text { Spes E (posisi } \\
\text { vertikal } \\
\text { denganE7018) }\end{array}$ & 48,0 & 63,0 & 69,7 & 60,26 \\
\hline 6 & $\begin{array}{l}\text { Spes F } \quad \text { (posisi } \\
\text { horizontal } \\
\text { E7018) }\end{array}$ & 61,1 & 38,9 & 57,4 & 52,53 \\
\hline 7 & Spesimen Kontrol & 121,8 & 125,5 & 126,7 & 124,6 \\
\hline
\end{tabular}

Tabel 2. Hasil Rata-Rata Kekuatan Tarik

\section{B. Pembahasan Hasil Pengujian Tarik}

Bahan yang digunakan dalam peelitian ini adalah baja karbon rendah TRS400. Alasan baja karbon rendah dipilih sebagai bahan penelitian karena baja ini merupakan bahan yang sangat banyak digunakan di industri serta bahan ini mudah diperoleh.

Spesimen yang di gunakan dalam penelitian ini ada 21 spesisem, dengan perincian: 3 kali percobaan untuk posisi pengelasan dibawah tangan dengan elektroda $\mathrm{E}$ 7016, 3 kali percobaan untuk posisi pengelasan dibawah tangan dengan elektroda E 7018, 3 kali percobaan untuk posisi pengelasan vertikal dengan elektroda E 7016, 3 kali percobaan untuk posisi pengelasan vertikal dengan elektroda E 7018, 3 kali percobaan untuk posisi pengelasan horizontal dengan elektroda E 7016, 3 kali percobaan untuk posisi pengelasan horizontal dengan elektroda E 7018, dan 3 kali lagi dilakukan dengan spesimen kontrol.

1. Sepesimen A (Posisi Bawah Tangan dengan Elektroda E 7016)

Spesimen A dilakukan pengelasan pada posisi bawah tangan dengan elektroda E 7016 kemudian dilakukan pengujian tarik, sehingga di peroleh nilai rata-rata kekuatan tarik sebesar $\mathbf{6 2 , 8 8 ~} \mathbf{~} \mathbf{g f} / \mathbf{m m}^{2}$.

Nilai kekuatan tarik pada spesimen ini merupakan nilai ke empat terendah, karena pada dasarnya elektroda jenis ini lebih bagus untuk penembusan, dan kurang baik untuk caping. 


\section{Sepesimen B (Posisi Vertikal dengan Elektroda E} 7016)

Spesimen B dilakukan pengelasan pada posisi vertikal dengan elektroda E 7016 kemudian dilakukan pengujian tarik, sehingga di peroleh nilai rata-rata kekuatan tarik sebesar $\mathbf{6 5 , 5 2 K g f} / \mathbf{m m}^{2}$.

Nilai kekuatan tarik pada spesimen ini merupakan nilai ke dua tertinggi, karena pada dasarnya elektroda jenis ini lebih bagus untuk penembusan, dan kurang baik untuk caping. Walaupun kurang bagus untuk caping tapi elektroda jenis cocok di gunakan untuk pengelas dengan posisi pengelasan vertikal karna memiliki kekuata tarik yang lebih tinggi dari spesimen yang dilakukan pengelasan dengan E 7018 pada posisi vertikal.

\section{Sepesimen C (Posisi Horizontal dengan Elektroda} E 7016)

Spesimen C dilakukan pengelasan pada posisi horizontan dengan elektroda E 7016 kemudian dilakukan pengujian tarik, sehingga di peroleh nilai rata-rata kekuatan tarik sebesar $63,39 \mathrm{Kgf} / \mathbf{m m}^{2}$.

Nilai kekuatan tarik pada spesimen ini merupakan nilai ke tiga tertinggi, karena pada dasarnya elektroda jenis ini lebih bagus untuk penembusan, dan kurang baik untuk caping. Walaupun kurang bagus untuk caping tapi elektroda jenis cocok di gunakan untuk pengelas dengan posisi pengelasan horizontal karna memiliki kekuata tarik yang lebih tinggi dari spesimen yang dilakukan pengelasan dengan E 7018 pada posisi horizontal.

\section{Sepesimen D (Posisi Bawah Tangan dengan Elektroda E 7018)}

Spesimen D dilakukan pengelasan pada posisi bawah tangan dengan elektroda E 7018 kemudian dilakukan pengujian tarik, sehingga di peroleh nilai rata-rata kekuatan tarik sebesar $\mathbf{5 2 , 2 6 K g f} / \mathbf{m m}^{2}$.

Nilai kekuatan tarik pada spesimen ini merupakan nilai paling rendah dari semua spesimen yang dilakukan pengujian, karena pada dasarnya elektroda jenis ini tidak bagus untuk penembusan, dan bagus untuk caping. Karna pada saat proses pengelasan elektroda jenis ini memiliki salutan yang lebih tebal dari pada elektroda E 7016, seingga pada saat proses pengelasan lebi duluan masuk salutannya dalam cela kampuh yang dibuat.

\section{Sepesimen E (Posisi Vertikal dengan Elektroda E 7018)}

Spesimen E dilakukan pengelasan pada posisi vertikal dengan elektroda E 7018 kemudian dilakukan pengujian tarik, sehingga di peroleh nilai rata-rata

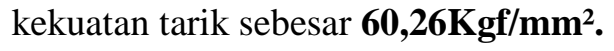

Nilai kekuatan tarik pada spesimen ini merupakan nilai ketiga paling rendah dari semua spesimen yang dilakukan pengujian, karena pada dasarnya elektroda jenis ini tidak bagus untuk penembusan, dan bagus untuk caping.

6. Sepesimen F (Posisi Horizontal dengan Elektroda E 7018)

Spesimen F dilakukan pengelasan pada posisi horizontal dengan elektroda E 7018 kemudian dilakukan pengujian tarik, sehingga di peroleh nilai rata-rata kekuatan tarik sebesar $\mathbf{5 2 , 5 3 K g f} / \mathbf{m m}^{2}$.

Nilai kekuatan tarik pada spesimen ini merupakan nilai ke dua paling rendah dari semua spesimen yang dilakukan pengujian, karena pada dasarnya elektroda jenis ini tidak bagus untuk penembusan, dan bagus untuk caping. Lebih baik elektorda jenis ini digunakan untuk caping tidak untuk penembusan.

\section{Spesimen Kontrol}

Spesimen kontrol tidak dilakukan pengelasan dan kemudian dilakukan pengujian tarik, sehingga didapat nilai kekuatan tarik rata-rata $124,69 \mathrm{Kg} / \mathbf{m m}^{2}$.

Nilai kekuatan tarik spesimen kontrol merupakan nilai paling tinggi dari semua spesimen yang dilakukan pengujian, hal ini disebabkan spesimen tidak menerima pelakuan pengelasan sehingga struktur yang di meliki oleh logam ini tidak berubah

Dari penelitian yang sudah dilakukan maka dapat dilihat bawah kekuatan tarik yang dimiliki oleh setiap spesimen yang dilakukan pengelasan tidak terlalu jauh berbeda kekuatan tariknya, akan tetapi spesimen kontrol yang memiliki kekuatan jauh berbeda dari spesimen yang di lakukan pengelasan.

\section{Grafik Hasil Penelitian}

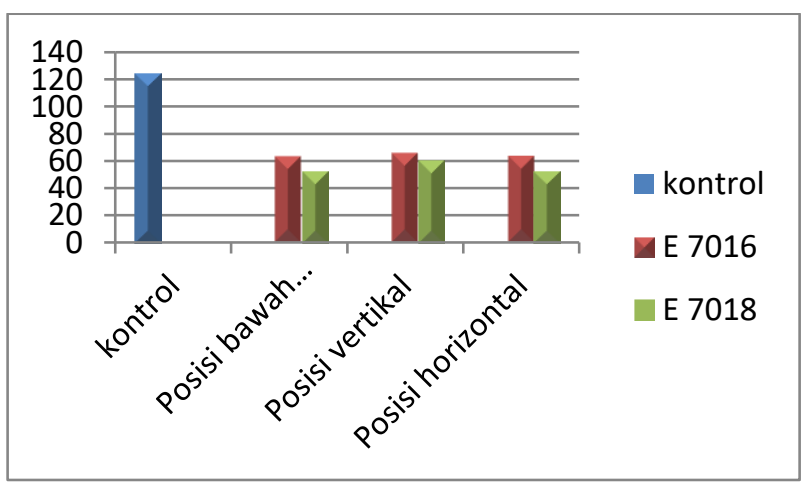

Gambar 1. Grafik Uji Tarik Baja TRS 400 Tanpa Pengelasan, dan Setelah Mengalami Pengelasan.

Berdasarkan gambar di atas dapat terlihat bahwa nilai kekuatan tarik paling baik pada spesimen yang dilas terdapat pada elektroda E 7016 dan pada posisi vertikal setelah dilakukan pengujian tarik,dengan demikian bahwa elektroda E 7016 dan posisi vertikal sangat cocok dipakai untuk mengelas baja TRS 400 . Pada pengujian tarik ini terdapat 3 kelompok spesime 
uji. Setiap spesimen dilakukan pengelasan dengan posisi bawah tangan, vertikal, dan horizontal dilas dengan dua jenis elektroda yang berbeda yaitu E 7016 dan E 7018.

\section{Kesimpulan}

Berdasarkan pengujian yang sudah dilakukan oleh peneliti pada baja karbon rendah TRS 400 dengan mengunkan posisi pengelasan yang berbeda yaitu posisi bawah tangan, posisi vertikal, dan posisi horizontal dengan elektroda E 7016 dan E 7018 maka dapat penulis ambil kesimpulan :

\section{Posisi Pengelasan}

Posisi pengelasan memberikan nilai yang nyata terhadap kekuatan tarik, dimana posisi pengelasa vertikal miliki nilai rata-rata kekuatan tarik yang lebih tinggi yaitu $\mathbf{6 5 , 5 2}\left(\mathbf{K g f} / \mathbf{m m}^{2}\right)$. dari tiga jenis posisi pengelasan yang peneliti lakukan yaitu, posisi bawah tangan, posisi vertikal, dan posisi horizontal. Dimana posisi yang berbeda akan memberi nilai yang berbeda juga.

\section{Jenis Elektroda}

Jenis elektroda juga sangat berpengaruh terhadap kekuatan tarik yang peneliti lakukan pada pengujian ini. Dimana nilai rata-rata kekuatan tarik yang paling tinggi didapat pada elektroda E 7016 yaitu $\mathbf{6 5 , 5 2}$ $\left(\mathbf{K g f} / \mathbf{m m}^{2}\right)$.Sehingga penggunaan elektroda yang kita gunakan harus sangat diperatikan sebelum melakukan pengelasan

\section{Hasil penelitian}

Setelah dilakukan penelitian, bahwa posisi pengelasan yang berbeda dengan elektroda yang berbeda akan memberikan kekuatan yang berbeda terhadap hasil pengelasan. Ini terbukti posisi pengelasan yang menghasilkan kekuatan tarik terbaik adalah posisi pengelasa vertikal dengan memakai elektroda E 7016 dengan nilai rata-rata terbaik $\mathbf{6 5 , 5 2}\left(\mathbf{K g f} / \mathbf{m m}^{2}\right)$, dibandingkan dengan posisi pengelasan yang lain yang dilakukan penelitian yaitu; posisi bawah tangan dan horizontal, serta elektroda E 7018.

\section{Daftar Pustaka}

Cary, H.B, 1998, Modern Welding Teknologi, Prentice Hall, New Jersey.

Daryanto.(2012). Teknik Las. Bandung: Alfabeta.

Edih Supardi. (1996). Pengujian logam. Bandung: Angkasa.

Erizon, N., Ardiyansyah, M., Jasman, J., \& A, Y. (2018). Effect of Cooling Media on Steel Hardness ST 37 On Conventional Lathe Process. Teknomekanik, 1(1), 6-11. Retrieved from http://teknomekanik.ppj.unp.ac.id/index.ph $\mathrm{p} /$ tekno/article/view/3

Fenny sartika. (2011). Perbedaan Kekuatan Material Hasil Pengelasan Logam St 37 Dengan Menggunakan Elektroda Tipe E 7016 Yang Di Panaskan Dengan Yang Tidak Di Panaskan. Skripsi. Padang: Universitas Negeri Padang.

Harsono Wiryosumarto, Toshie Okumura. (2008). Teknologi Pengelasan Logam. Jakarta: Pradya Paramita.

I Gusti Ngurah Nitya Santhiarsa, I Nyonyabudiarsa. (2008) Pengaruh Proses Pengelasan dan Gerakan Elektroda Kekerasan Las Baja JIS SCC 41. Jurnal Ilmiah. Bukit Jimbran Bali: Universitas Udayana.

Nabawi, R. A. (2012). Analisis kekuatan Tarik Komposit Polimer Berpenguat Serat Eglass yang Diberi Perlakuan Alkali (NAOH). Skripsi: Universitas Negeri Padang

Sugiyono. (2008). Metode Penelitian Kuantitatif Kualitatif dan $R \& D$. Bandung: Alfabeta.

Tira Steel. (1974). Katalog Wear Resistant Steel. Jakarta: PT Tira Austenite Tbk.

UNP. (2011). Buku Pedoman Penulisan Tugas Akhir / Skripsi. Padang: Universitas Negeri Padang.

Yondri, S., Nabawi, R. A., \& Islami, S. (2017, October). Utilization of Potential Water Energy in Irrigation Channels for PicoHydro Power Plant. In International Conference of Applied Science on Engineering, Business, Linguistics and Information Technology (pp. 161-163). ICo-ASCNITECH.

Yondri, S., Nabawi, R. A., Sunitra, E., Islami, S., \& Asrul, J. (2017, October). The Machine Punch Mulch: A Pneumatic Pierching and Control With Fuzzy Logic Control. In International Conference of Applied Science on Engineering, Business, Linguistics and Information Technology (pp. 148-152). ICoASCNITECH.

Wahyudin K dan Wahjoe Hidayat.(1978:46). Pengetahuan Logam 2. Jakarta : Departemen Pendidikan Dan Kebudayaan. 
https://www.academia.edu/12139352/Prosedur Peng ujian Uji Tarik Baja (di akses tgl 2 nov 2016 jam 18:59 wib).

http://2.bp.blogspot.com/f6wKEM6FTrE/UXVOzhn VIXI/AAAAAAAAAl8/4IBbCd0HTK4/s160 0/diagram+cct.jpg (di akses 30 desember 2016 jam 21.17 WIB).

https://www.google.co.id/webhp?sourceid=chromeinstant\&ion $=1 \&$ espv $=2 \&$ ie $=$ UTF-

$\underline{8 \# \mathrm{q}=\text { gambar+diagram+metarulgi+pengelasan }}$ (di akses 30 desember 2016 jam $21.17 \mathrm{~W}$ 
